\title{
Desequilíbrio quantitativo na formação de odontólogos no Brasil: trajetória de 1995 a 2015
}

\author{
Quantitative imbalance in dental education and distribution of odontologists \\ in Brazil: trajectory from 1995 to 2015
}

\begin{abstract}
Andréa Lanzillotti Cardoso, ${ }^{1}$ Ana Luiza Stiebler Vieira, ${ }^{2}$ Urubatan Vieira de Medeiros ${ }^{1}$
${ }_{1}^{1}$ Departamento de Odontologia Preventiva e Comunitária, Faculdade de Odontologia, Universidade do Estado do Rio de Janeiro, Rio de Janeiro, RJ, Brasil

${ }^{2}$ Departamento de Administração e Planejamento em Saúde, Fundação Oswaldo Cruz, Rio de Janeiro, RJ, Brasil

- Os autores declaram que não há conflito de interesse.
\end{abstract}

\section{Resumo}

Objetivo: analisar a trajetória da graduação em Odontologia no Brasil; apontar a ociosidade de vagas e identificar os atuais recursos humanos de odontólogos. Material e Métodos: o estudo quantitativo-descritivo utilizou dados públicos do Instituto Nacional de Estudos e Pesquisas Educacionais Anísio Teixeira na análise da oferta pública e privada de cursos, vagas e concluintes no período de 1995 a 2015, nas regiões brasileiras, bem como a ociosidade de vagas através da relação dos totais em cada ano, das vagas x ingressos. Através do Conselho Federal de Odontologia, identificou-se até dezembro de 2016 a atual disponibilidade e distribuição de odontólogos no país. Resultados: observou-se grande expansão, iniquidade geográfica e privatização da formação; uma significativa ociosidade de vagas e, ainda, insuficiente disponibilidade e inadequada distribuição de recursos humanos no país para a assistência odontológica. Conclusão: destaca-se que a grande expansão do ensino através da sua privatização, a formação de odontólogos concentrada na região Sudeste, aliada à ociosidade de vagas, geram um desequilíbrio na oferta de profissionais para a assistência odontológica de forma equânime conforme preconiza o Sistema Único de Saúde.

Palavras-chave: Recursos humanos em saúde; Odontólogos; Formação profissional.

\begin{abstract}
Objective: this study aimed to analyze the trajectory of undergraduate dentistry in Brazil, refer to the insufficient admissions for the course, and identify the recent availability and distribution of dentists in the country. Material and Methods: this quantitative-descriptive study used the public data from the National Institute of Educational Studies and Research Anísio Teixeira to analyze the public and private offer of dentistry courses, admission vacancies, and graduated professionals from 1995 to 2015, in the Brazilian regions, as well as the idleness of vacancies through the ratio of totals in each year, of vacancies $x$ admissions. Through the Federal Council of Dentistry, the recent availability and distribution of dentists in the country was identified until December 2016. Results: there was great expansion of dental courses, geographic inequality, and privatization of formation; significant job vacancy for dental care; and insufficient availability and inadequate distribution of dentists in the country. Conclusion: notably, the great expansion of dental education through private courses, dental training concentrated in the southeast part of the country, and the insufficient admissions in certain regions, lead to an unequal distribution of dental care professionals, according to the Brazilian Unified National Health System.
\end{abstract}

Keywords: Health manpower; Dentists; Staff development.

\section{Introdução}

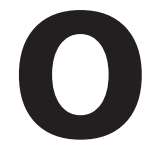
ensino superior no Brasil foi reestruturado através da Lei de Diretrizes e Bases da Educação Nacional de $1996(\mathrm{LDB})^{1}$ a qual possibilitou o crescimento de cursos em todas as áreas do conhecimento tendo em vista as flexibilizações outorgadas ao sistema de ensino, tais como: a autonomia didático-científica; a liberdade na composição da carga horária para integralização dos currículos; a liberdade de abertura, fixação de vagas e fechamento de cursos; a flexibilização na forma de ingresso no ensino superior; e a autonomia administrativa e de gestão financeira das instituições de ensino. A revisão da LDB em $2014^{2}$ manteve inalteradas estas autonomias e liberdades na educação superior. Aliada a estas flexibilizações, a maior acessibilidade ao ensino superior a partir dos anos 2000 como política de Estado, também corroborou para a expansão dos cursos de graduação em todas as áreas do conhecimento.

A Resolução CNS/CES no 3, de 19 de fevereiro de 2002, ${ }^{3}$ específica para o curso de Odontologia, instituiu as Diretrizes Curriculares Nacionais (DCNs) que definiram o perfil profissional, as competências e habilidades, os conteúdos curriculares, estágios e atividades complementares, a organização do curso e o seu acompanhamento e avaliação. O documento também instituiu a intersetorialidade entre os Ministérios da Saúde e da Educação para orientar programas conjuntos e decisões relacionadas à formação desses profissionais.

Com base no conceito ampliado de saúde, já não havia mais possibilidade de entender a educação descontextualizada do aspecto social. As DCNs trouxeram importantes mudanças nos cursos de graduação em Odontologia, no intuito de formar profissionais adequados às necessidades de saúde da população e do Sistema Único de Saúde (SUS), que por apresentar como um de seus princípios a universalidade, garantiu a abertura de postos de trabalho para esses profissionais.

A reforma do setor educativo, segundo análise do pe- 
ríodo de 1995 a 2003 de Oliveira et al., ${ }^{4}$ resultou em marcantes mudanças na formação dos odontólogos no país: o crescimento de cursos, a concentração geográfica e a forte tendência de privatização do ensino. Tais resultados são corroborados pelos estudos da trajetória da graduação em Odontologia de Haddad et al..$^{5}$ e de Pierantoni et al., ${ }^{6}$ os quais também destacaram a concentração desta formação em regiões brasileiras mais desenvolvidas e, ainda, sinais de ociosidade de vagas.

Vale ressaltar que, à medida em que o mercado de trabalho se expande no setor público e da constatação de que nos dias atuais os recém-formados aspiram por inserção tanto no mercado privado quanto público, a implantação das DCNs assume grande importância no aperfeiçoamento do SUS.?

Considerando que as análises supracitadas finalizaram em 2003, 2004 e 2010, objetivou-se analisar a trajetória da formação dos odontólogos relativa à oferta de cursos, vagas e concluintes (públicos, privados e nas regiões brasileiras) de 1995 até o ano de 2015; apontar a ociosidade das vagas e identificar a disponibilidade e distribuição nacional dos cirurgiões-dentistas no país.

\section{Material e Métodos}

Optou-se pelo método de pesquisa quantitativo-descritivo utilizando os dados públicos de cada ano, do Censo da Educação Superior do Instituto Nacional de Estudos e Pesquisas Educacionais Anísio Teixeira (INEP), ${ }^{8}$ do Ministério da Educação. A escolha do período (1995 a 2015) corresponde aos anos anteriores (1995 e 1996) à promulgação da LDB de $1996^{1}$ e, após implementação, consolidação e consequências desta Lei para a graduação em tela (1997 a 2015), como também da política do Estado de maior acesso ao ensino superior a partir dos anos 2000. A finalização em 2015, se deve à última disponibilidade de dados do INEP. Para atualizar a trajetória do crescimento, da privatização e da concentração geográfica, buscou-se os dados de cursos, vagas e concluintes da Odontologia nas instituições públicas e privadas de ensino e nas regiões brasileiras.

Para apontar a ociosidade de vagas da Odontologia lançou-se mão da relação vagas $\mathrm{x}$ ingressos em todo o período. E, ainda, com vistas a identificar a disponibilidade e distribuição nacional dos cirurgiões-dentistas utilizou-se os dados públicos mais atuais destes recursos humanos disponíveis nas regiões e unidades de federação, ou seja, o "estoque" de cirurgiões-dentistas registrados até dezembro de 2016, no Conselho Federal de Odontologia. ${ }^{9}$

Os dados foram apresentados e analisados através de frequências tanto absoluta quanto relativa tendo em vista os objetivos propostos.

No estudo utilizou-se fontes públicas e dados secundários e de acesso público, bem como, não se abordou sujeitos na investigação.

\section{Resultados}

\section{Expansão, Privatização e Concentração Geográfica da Graduação em Odontologia no País}

Através dos dados da Tabela 1 pode-se evidenciar um crescimento total de $164,3 \%$ dos cursos de graduação em Odontologia no período de 1995 a 2015, o que revela o impacto da política de expansão e flexibilização do ensino superior advinda da LDB de $1996^{1}$ corroborada pelo Plano Nacional de Educação (PNE) de 2001 a 2010, ${ }^{10}$ que objetivou prover a oferta de educação superior até o final da década para $30 \%$ da população de 18 a 24 anos; e ainda pelo Plano Nacional de Educação (PNE) de 2014 a $2024^{11}$ que prossegue com o mesmo escopo, porém aumentado para $33 \%$ a inclusão da população de 18 a 24 anos nas graduações brasileiras.

Tabela 1. Cursos e concluintes da graduação em Odontologia por anos e entidades mantenedoras

\begin{tabular}{|c|c|c|c|c|c|c|}
\hline \multirow{2}{*}{ Anos } & \multicolumn{3}{|c|}{ Cursos } & \multicolumn{3}{|c|}{ Concluintes } \\
\hline & Pub. & Priv. & Total & Pub. & Priv. & Total \\
\hline 1995 & 46 & 45 & 91 & 3.064 & 3.900 & 6.964 \\
\hline 1996 & 49 & 44 & 93 & 3.165 & 3.885 & 7.050 \\
\hline 1997 & 48 & 52 & 100 & 3.134 & 4.479 & 7.613 \\
\hline 1998 & 49 & 68 & 117 & 3.246 & 4.464 & 7.710 \\
\hline 1999 & 49 & 82 & 131 & 2.909 & 5.102 & 8.011 \\
\hline 2000 & 51 & 91 & 142 & 2.867 & 4.875 & 7.742 \\
\hline 2001 & 52 & 101 & 153 & 3.089 & 5.676 & 8.765 \\
\hline 2002 & 52 & 107 & 159 & 2.974 & 6.307 & 9.281 \\
\hline 2003 & 53 & 118 & 171 & 3.252 & 6.596 & 9.848 \\
\hline 2004 & 54 & 120 & 174 & 2.928 & 6.12 & 9.056 \\
\hline 2005 & 54 & 122 & 176 & 3.151 & 5768 & 8919 \\
\hline 2006 & 56 & 126 & 182 & 3.135 & 5398 & 8533 \\
\hline 2007 & 57 & 133 & 190 & 3.145 & 5200 & 8345 \\
\hline 2008 & 7 & 36 & 193 & 3.271 & 5458 & 8729 \\
\hline 2009 & 57 & 138 & 195 & 3.071 & 5439 & 8510 \\
\hline 2010 & 58 & 143 & 201 & 3.282 & 5648 & 8930 \\
\hline 2011 & 60 & 149 & 209 & 3.185 & 6452 & 9637 \\
\hline 2012 & 66 & 149 & 215 & 3.358 & 6911 & 10.269 \\
\hline 2013 & 68 & 151 & 219 & 3.316 & 6864 & 10.180 \\
\hline 2014 & 67 & 163 & 230 & 3.411 & 7357 & 10.768 \\
\hline 2015 & 64 & 177 & 241 & 3.313 & 9578 & 12.891 \\
\hline Total & - & - & - & 66.266 & 121.485 & 187.751 \\
\hline
\end{tabular}

Fonte: INEP. Censo da Educação Superior, 1995-2015. 
Percebe-se na Tabela 1, que no período de 1995 a 2015, o crescimento da oferta na Odontologia foi de 150 cursos, ou seja, em 20 anos, uma média anual de 7,5 novos cursos cuja expansão foi comandada primordialmente pelas instituições privadas de ensino a partir do ano de 1998. Se em 1995 estas participavam com 49,4\% do total dos cursos, em 2005 passaram para $69,3 \%$ e em 2015 cresceram sua oferta para $73,4 \%$ do total da graduação em Odontologia no país. Neste último ano, do total de 241 cursos, 177 foram ofertados nas instituições privadas de ensino, como demonstra a Tabela 1, e apenas 64 cursos nas instituições públicas. Entre estas últimas, a maior oferta encontrava-se nas universidades federais com 32 cursos, 24 cursos nas universidades estaduais e somente 8 cursos nas municipais.

Observou-se a permanência da iniquidade geográfica da oferta dos cursos de Odontologia. Em 1995, a região Sudeste ofertava $57,1 \%$ do total dos cursos (principalmente São Paulo com 30,8\%, Minas Gerais 13,2\% e Rio de Janeiro 12,1\%); a região Sul 17,6\% (principalmente o Paraná com 8,8\% e o Rio Grande do Sul com 6,6\%); a região Nordeste $16,5 \%$ (Pernambuco com 4,4\% e o restante da oferta distribuída nos outros oito estados); a região Centro-Oeste 6,6\% (em três estados e no Distrito Federal) e a região Norte com apenas 2,2\% do total dos cursos no país (distribuídos em sete estados). Em 2015, houve uma retração da concentração da oferta de cursos no Sudeste, mas esta ainda ofertando $43,5 \%$ do total dos cursos (principalmente São Paulo com 23,0\%, Minas Gerais $11,0 \%$ e Rio de Janeiro 7,8\%); o Nordeste 20,9\% (sendo na Bahia 4,8\%, Pernambuco e Ceará 3,1\% cada, e o restante $9,9 \%$ distribuídos nos outros seis estados da região); o Sul 19,1\% (sendo no Paraná 7,8\%, Rio Grande do Sul 6,5\%, e Santa Catarina 4,8\%); o Norte 9,1\% (principalmente no Amazonas com 2,6\% e Tocantins 2,2\%, e o restante $4,3 \%$ distribuídos nos outros cinco estados) e o Centro-Oeste 7,4\% (principalmente no Distrito Federal e Mato Grosso com uma oferta de 2,2\% cada, e o restante 3,0\% distribuídos nos outros dois estados da região).

A oferta de vagas para a Odontologia acompanhou a dinâmica dos cursos quanto ao crescimento, privatização e concentração geográfica. Se em 1995 o seu total era de 8.521 vagas, em 2005 passou para 16.121, e em 2015 para 27.395 vagas; de 1995 a 2015, o sistema de ensino brasileiro ofertou um total de 351.644 vagas para a graduação em Odontologia, conforme observado na Tabela 2.
Tabela 2. Ociosidade de vagas na graduação em Odontologia por anos

\begin{tabular}{|c|c|c|c|c|}
\hline \multirow{2}{*}{ Anos } & \multirow{2}{*}{ Vagas } & \multirow{2}{*}{ Ingressos } & \multicolumn{2}{|c|}{ Ociosidade de vagas } \\
\hline & & & $\%$ & $\mathbf{n}$ \\
\hline 1995 & 8.521 & 8.252 & 3,1 & 269 \\
\hline 1996 & 8.476 & 8.247 & 2,7 & 229 \\
\hline 1997 & 9.643 & 9.747 & 1,1 & 104 \\
\hline 1998 & 11.267 & 11.141 & 1,1 & 126 \\
\hline 1999 & 13.304 & 12.048 & 9,4 & 1256 \\
\hline 2000 & 14.051 & 11.834 & 15,8 & 2217 \\
\hline 2001 & 14.209 & 11.585 & 18,5 & 2624 \\
\hline 2002 & 15.701 & 11.653 & 25,8 & 4048 \\
\hline 2003 & 16.333 & 11.184 & 31,5 & 5149 \\
\hline 2004 & 15.733 & 10.703 & 32,0 & 5030 \\
\hline 2005 & 16.121 & 11.203 & 30,5 & 4918 \\
\hline 2006 & 16.711 & 11.408 & 31,7 & 5303 \\
\hline 2007 & 18.266 & 11.819 & 35,3 & 6447 \\
\hline 2008 & 19.157 & 13.317 & 31,9 & 5840 \\
\hline 2009 & 19.424 & 12.980 & 33,2 & 6444 \\
\hline 2010 & 19.069 & 14.728 & 22,8 & 4341 \\
\hline 2011 & 20.861 & 16.636 & 20,2 & 4225 \\
\hline 2012 & 20.589 & 20.624 & 0,2 & 35 \\
\hline 2013 & 21.667 & 21.850 & 0,8 & 183 \\
\hline 2014 & 25.146 & 23.920 & 4,9 & 1226 \\
\hline 2015 & 27.395 & 25.265 & 7,8 & 2130 \\
\hline Total & 351.644 & 290.144 & 17,5 & 269 \\
\hline
\end{tabular}

Fonte: INEP. Censo da Educação Superior, 1991-2015.

As instituições privadas de ensino com menor número de cursos em 1995, já ofertavam 62,0\% das vagas, em 2015 com maior número de cursos passaram a ofertar $82,1 \%$ das vagas no país.

As vagas em 2015 também estavam concentradas no Sudeste em 49,1\% do seu total (principalmente em São Paulo com 28,9 \%, Minas Gerais 11,1\%, Rio de Janeiro 7,6\%); no Nordeste $18,6 \%$ (principalmente na Bahia com 4,6\%, Pernambuco 3,3 \%, Ceará 2,8\%, Maranhão e Paraíba com $1,9 \%$ cada, e o restante de $4,1 \%$ distribuídos nos outros quatro estados da região); no Sul 15,1\% (Paraná 6,3\% Rio Grande do Sul com 4,6\%, e Santa Catarina 4,2\%); no Norte $10,1 \%$ (Amazonas com 3,1\% das vagas e o restante da região ou 7,0\%, distribuídos em seis estados) e no Centro -Oeste 7,1\% (Distrito Federal 2,1\%, Mato Grosso 2,0\%, e o restante de 3,0\%, nos dois outros estados da região).

Ainda pela Tabela 1 percebe-se que de 1995 a 2015 houve um crescimento de $85,1 \%$ de concluintes. Do total no período de 187.751 odontólogos, $64,7 \%$ se graduaram em instituições privadas de ensino. Já em 1995, a maioria 
(56,0\%) dos concluintes se formaram em instituições privadas, passando para 74,3\% em 2015.

A distribuição geográfica dos concluintes acompanhou a dinâmica da oferta de cursos e vagas. Em 1995, a região Sudeste concentrou em $69,2 \%$ do total dos concluintes no país (principalmente em São Paulo com 36,0\%, Minas Gerais com $20,6 \%$ e Rio de Janeiro 12,2\%); o Sul 14,3\% (principalmente Rio Grande do Sul 6,4\% e Paraná 5,8\%); o Nordeste formou 10,5\%, dos profissionais (Pernambuco 2,4\%, Paraíba $1,9 \%$, Bahia $1,6 \%$ e o restante, ou $4,6 \%$ distribuídos nos outros seis estados); o Centro-Oeste 4,5\% (Goiás 1,7\%, Distrito federal $1,4 \%$ e o restante de $1,4 \%$ nos dois outros estados) e o Norte $1,5 \%$ (com concluintes apenas em dois estados, $1,1 \%$ no Pará e $0,4 \%$ no Amazonas).

Em 2015, houve uma retração da região Sudeste embora ainda ofertando 49,8\% do total de concluintes no país (principalmente em São Paulo com 29,0\%, Minas Gerais 12,0\% e Rio de Janeiro 7,7\%); o Sul 17,5\% (Paraná 7,9\% Rio Grande do Sul com 6,2\% e Santa Catarina 3,4\%); o Nordeste 17,1\% (Bahia 4,0\%, Pernambuco e Ceará com 2,2\% cada e o restante de $8,7 \%$ distribuídos nos outros seis estados da região); o Norte $9,3 \%$ (Amazonas 3,0\%, Pará 1,9\% e o restante 4,4\% distribuídos nos outros cinco estados da região) e o Centro-Oeste 6,3\% (Distrito Federal com 2,3\%, Goiás 1,9\% e o restante, ou $2,1 \%$ nos dois outros estados da região).

\section{Ociosidade de Vagas}

$\mathrm{Na}$ Tabela 2 pode-se constatar a ociosidade de vagas na graduação em Odontologia. Assim, na relação vagas $\mathrm{x}$ ingressos no período de 1995 a 2015, esta ociosidade chegou ao patamar de $17,5 \%$ do total das vagas ofertadas, ou de 61.500 vagas não preenchidas.

É importante ressaltar que a ociosidade de vagas se exacerba entre os anos 2001 e 2011. A partir deste, sofre uma queda, podendo ser em consonância com a ampliação do Fundo de Financiamento ao Estudante do Ensino Superior (FIES), ${ }^{12}$ programa do Ministério da Educação destinado a financiar a graduação de estudantes matriculados em instituições privadas. Atualmente, durante o período de duração do curso e até 18 meses do término do mesmo, o estudante paga trimestralmente o valor máximo de $\mathrm{R} \$ 150,00$ (cento e cinquenta reais), referente ao pagamento de juros incidentes sobre o financiamento. Finalizado esse período, o saldo devedor do graduado poderá ser parcelado em até 3 (três) vezes. Desta forma, se o curso durou quatro anos, o profissional terá até 12 anos para quitar o saldo devedor.

Também contribuindo para um maior acesso à educação superior em instituição privada, se observa o Programa Universidade para Todos (PROUNI) ${ }^{13}$ como estratégia de manutenção do nível de matrículas através da concessão de bolsas integrais e parciais de estudo. Este, dirigido aos estudantes egressos do ensino médio com renda familiar per capita máxima de três salários mínimos.

Já no setor público, a expansão do ensino superior conta com o Programa de Apoio a Planos de Reestruturação e Expansão das Universidades Federais (REUNI), ${ }^{14}$ que busca ampliar o acesso e a permanência na educação superior. No entanto, o REUNI é limitado à previsão orçamentária do Ministério da Educação, não havendo a garantia da efetividade, da continuidade e do cumprimento de desembolsos acordados desde a sua instituição em 2007.

\section{Odontólogos no Brasil}

De acordo com Pinto, ${ }^{15}$ em 1980, o Brasil contava com 61.628 odontólogos inscritos no Conselho Federal de Odontologia (CFO). Em 1989 este número se elevou para 101.880 profissionais. Assim, conforme o autor, no intervalo de uma década (1980-1989) o estoque de profissionais cresceu extraordinariamente na ordem de $65,3 \%$ ao passo que a população brasileira aumentava em 20\%. Em 1960 a relação odontólogo por 1.000 habitantes era igual a 0,33; em 1970, essa proporção passou para 0,36; em 1980 ela foi a 0,51; e em 1990 passou para 0,70. Ainda na análise de Pinto, ${ }^{15} \mathrm{em}$ 2013 havia uma relação 1,36 odontólogo para cada 1.000 habitantes, ou seja, o número de odontólogos registrados no CFO em outubro de 2013 era de 263.421, enquanto a população brasileira estimada à época era de 193,9 milhões de habitantes.

Pode-se dizer que essa relação oscila muito entre as regiões. Através dos dados de recursos humanos de cirurgiões-dentistas registrados em dezembro de 2016 no CFO, ${ }^{9}$ pode-se constatar a dinâmica da oferta da graduação em Odontologia tendo como consequência a iniquidade geográfica da distribuição dos profissionais no território nacional. Desta forma, se concentravam na região mais desenvolvida, ou seja, o Sudeste, seguida das regiões Sul e Nordeste. Chama a atenção os estados do Norte, exceto o Pará e ainda o estado de Sergipe, os quais contavam com menos de $1,0 \%$ do total dos odontólogos do país. Sob o ponto de vista de saúde pública, esta distribuição revela a dificuldade no acesso à assistência odontológica para grande parte da população brasileira; em que pese todos os esforços enveredados pela Política Nacional de Saúde bucal, em vigor. Assim, em dezembro em 2016, através da projeção da população do Instituto Nacional de Geografia e Estatísticas (IBGE) ${ }^{16}$ e dos dados de recursos humanos do CFO, ${ }^{9}$ o Brasil ainda contava com 1,3 odontólogo por 1.000 habitantes, sendo de 1,8 na região Sudeste; no Sul e no Centro-Oeste de 1,6 em cada região e no Nordeste e no Norte de 0,8 odontólogo por 1.000 habitantes em cada região.

Para melhor elucidação apresentamos a Tabela 3 que mostra, por Estado da Federação, o número de odontólogos registrados no CFO em dezembro de 2016.

Rev. Bras. Odontol., Rio de Janeiro, v. 74, n. 1, p. 114-9, abr./jun. 2017 
Tabela 3. Odontólogos nas regiões e unidades da federação

\begin{tabular}{|c|c|c|}
\hline \multirow{2}{*}{$\begin{array}{l}\text { Brasil, regiões e unidades } \\
\text { da federação }\end{array}$} & \multicolumn{2}{|c|}{ Odontólogos } \\
\hline & No & $\%$ \\
\hline BRASIL & 285.659 & 100,0 \\
\hline NORTE & 14.717 & 5,1 \\
\hline Acre & 644 & 0,2 \\
\hline Amapá & 657 & 0,3 \\
\hline Amazonas & 3.796 & 1,3 \\
\hline Pará & 4.951 & 1,7 \\
\hline Rondônia & 2.059 & 0,7 \\
\hline Roraima & 631 & 0,2 \\
\hline Tocantins & 1.979 & 0,7 \\
\hline NORDESTE & 44.445 & 15,6 \\
\hline Alagoas & 2.722 & 1,0 \\
\hline Bahia & 11.434 & 4,0 \\
\hline Ceará & 6.453 & 2,2 \\
\hline Maranhão & 3.739 & 1,3 \\
\hline Paraíba & 4.184 & 1,5 \\
\hline Pernambuco & 7.658 & 2,7 \\
\hline Piauí & 2.783 & 1,0 \\
\hline Rio G. do Norte & 3.564 & 1,2 \\
\hline Sergipe & 1.908 & 0,7 \\
\hline SUDESTE & 154.608 & 54,1 \\
\hline Espírito Santo & 5.510 & 1,9 \\
\hline Minas Gerais & 33.387 & 11,7 \\
\hline Rio de Janeiro & 30.455 & 10,7 \\
\hline São Paulo & 85.256 & 29,8 \\
\hline SUL & 46.858 & 16,4 \\
\hline Paraná & 18.022 & 6,3 \\
\hline Rio G. do Sul & 17.530 & 6,1 \\
\hline Santa Catarina & 11.306 & 4,0 \\
\hline C. OESTE & 25.031 & 8,8 \\
\hline Distrito Federal & 6.982 & 2,4 \\
\hline Goiás & 9.851 & 3,5 \\
\hline Mato Grosso & 4.343 & 1,5 \\
\hline Mato G. do Sul & 3.855 & 1,4 \\
\hline
\end{tabular}

Fonte: CFO, 2016.

\section{Discussão}

Evidenciou-se um crescimento total de $164,3 \%$ dos cursos de graduação em Odontologia no período de 1995 a 2015 (de 91 para 241), fruto das políticas de flexibilização e de incentivo para o acesso ao ensino superior como a LDB de $1996^{1}$ e os PNEs..$^{10,11}$ As quais propiciaram também a privatização da graduação em Odontologia, chegando as instituições privadas em 2015 com uma participação de 73,4\% (do total de 241 cursos) da oferta de cursos, de 82,1\% (do total de 27.395 vagas) das vagas e de $74,3 \%$ (do total de 12.891) dos con- cluintes. Se a privatização do ensino foi apontada como tendência por Oliveira et al., ${ }^{4}$ tornou-se uma forte característica do ensino da Odontologia no país.

Como já haviam detectado Haddad et al. ${ }^{5}$ e Pierantoni et al., ${ }^{6}$ como sinais, a ociosidade de vagas pôde ser mais evidenciada no período de 1995 a 2015 na graduação em Odontologia. Embora programas de incentivo fossem implementados, verificou-se em todo o período, $17,5 \%$ de ociosidade do total das vagas (ou 61.500 vagas ociosas) com patamares elevados entre os anos de 2001 a 2011 (quando se observou a maior expansão dos cursos), mas recuperando o preenchimento das vagas até 2015. Como a oferta tornou-se essencialmente privada, há que se considerar o alto custo das mensalidades como um dos fatores para o não preenchimento das vagas e, ainda, a insuficiência e a inacessibilidade aos programas de financiamento públicos e concessão de bolsas (FIES ${ }^{12}$ e o $\mathrm{PROUNI}^{13}$ ) para os estudantes nas instituições privadas de ensino.

Além das marcadas características do ensino da Odontologia no país, de grande expansão, da ociosidade de vagas e de sua privatização, destaca-se também a iniquidade geográfica do ensino dada a concentração em 2015, de 43,5\% (do total de 241) da oferta de cursos na região Sudeste, embora tenha havido ligeira desconcentração em relação a 1995. A situação dos cursos, vagas e egressos, no Brasil, pode ser caracterizada por um desequilíbrio geográfico e quantitativo, dado o maior desenvolvimento socioeconômico; assim em 2015, os estabelecimentos formadores, concentravam-se na região Sudeste, principalmente nos estados de São Paulo (23,0\% do total dos cursos), Minas Gerais (11,0\%) e Rio de Janeiro (7,8\%). Apenas o estado de São Paulo ofertava mais cursos do que cada região brasileira (Nordeste 20,9\%; Sul 19,1\%; Norte 9,1\% e Centro-Oeste 7,4\%).

A iniquidade geográfica da oferta da graduação reflete na disponibilidade e distribuição dos cirurgiões-dentistas no território nacional, com uma concentração de $54,1 \%$ dos recursos humanos na região Sudeste. Embora tenha-se verificado grande expansão da oferta de ensino, esta ainda não se traduziu na suficiência quantitativa para a assistência odontológica à população brasileira como revela a relação total de apenas de 1,3 odontólogos por 1.000 habitantes. E ainda há que se considerar que a inscrição nos Conselhos Regionais de Odontologia é de caráter cumulativo e que também podem existir inscrições secundárias.

A Política Nacional de Saúde Bucal, em seus investimentos para a criação de Equipes de Saúde Bucal e a manutenção destas, vem contribuindo para a pulverização desses profissionais. No entanto, a fixação no interior enfrenta um grande problema não só para a Odontologia. De acordo com Cardoso, ${ }^{17}$ os profissionais não vislumbram a fixação nas cidades do interior, admitem apenas o trabalho por tempo determinado. $\mathrm{Na}$ verdade, sentem a necessidade de se an- 
corarem em um lugar que lhes ofereça a oportunidade de se aprofundar em estudos de pós-graduação, e de acesso à cultura e ao lazer.

\section{Conclusão}

Visualizando toda a trajetória da formação de odontólogos no Brasil com marcadas características de grande expansão de cursos, vagas e concluintes através da sua privatização, a sua concentração na região Sudeste, aliada à ociosidade de vagas, embora nos últimos anos esta venha se recuperando, conclui-se que tal cenário gera um desequilíbrio na oferta de profissionais para a assistência odontológi- ca de forma equânime conforme preconiza o Sistema Único de Saúde.

Torna-se como desafios, além da garantia da qualidade do ensino, a necessidade de políticas de recursos humanos dirigidas ao planejamento, reorganização e ordenamento da formação dos odontólogos no país, de forma articulada entre os setores da saúde, da educação e das corporações da Odontologia, em direção à uma assistência odontológica comprometida com os princípios da universalidade de acesso, a equidade e hierarquização, a descentralização e regionalização e, ainda, a resolubilidade da assistência à saúde bucal da população brasileira.

\section{Referências}

1. Brasil. Ministério da Educação. Lei no 9.394 de 20 de dezembro de 1996. Lei das Diretrizes e Bases da Educação Nacional (LDB). Estabelece as diretrizes e bases da educação nacional. Brasília: ME; 1996.

2. Brasil. Câmara dos Deputados. LEI no 9.394 de 20 de dezembro de 1996. Atualizada em 20 de maio de 2014. Lei de Diretrizes e Bases da Educação Nacional (LDB). 9a ed. Brasília: Edições Câmara; 2014.

3. Brasil. Ministério da Educação. Resolução CNS/CES no 3, de 19 de fevereiro de 2002. Institui Diretrizes Curriculares Nacionais do Curso de Graduação em Odontologia. Brasília: DOU; 4 março 2002. Seção 1. P.10.

4. Oliveira ES, Vieira ALS, Cardoso AL, Amâncio Filho A, Garcia ACP. Odontologia. In: Vieira ALS, Amâncio Filho A, editores. Dinâmica das Graduações em Saúde no Brasil: subsídios para uma política de recursos humanos. Brasília: Ministério da Saúde; 2006. P. 89-112.

5. Haddad AE, Pierantoni CR, Ristoff D, Xavier IM, Giolo J, Silva LB. A Trajetória dos Cursos de Graduação em Saúde 1991-2004. Odontologia. Brasília: INEP, 2006;11.

6. Pierantoni CR, França T, Magnago C, Miranda RG. Graduações em Saúde no Brasil: 2000-2010. Rio de Janeiro: Cepesc: IMS/UERJ; 2012.

7. Cardoso AL. Mercado de Trabalho dos Odontólogos e Expectativas dos graduandos. [dissertação]. Rio de Janeiro: Escola Nacional de Saúde Pública/FIOCRUZ, Programa de Pós graduação em Saúde Pública, 2007.

8. Instituto Nacional de estudos e Pesquisas Educacionais Anísio Teixeira (INEP). Censo da Educação Superior. Brasília: INEP, 1991-2015.

9. CFO: Conselho Federal de Odontologia [Internet]. Dados Estatísticos. [acesso em 30 dez 2016] Disponível em: cfo.org.br/impressa/dados-estatísticos/ 10. Brasil. Presidência da República. Lei no 10.172 de 9 de janeiro de 2001. Plano
Nacional de Educação (PNE 2001-2010). Aprova o Plano Nacional de Educação para o decênio de 2001 a 2010 e dá outras providências. Brasília: DOU; 10 janeiro 2001. Seção 1. P. 120.

11. Brasil. Presidência da República. Lei no 13.005 de 25 de junho de 2014 (PNE 2014-2024). Aprova o Plano Nacional de Educação de 2014 a 2024 e dá outras providências. Brasília: DOU; 26 junho 2014. Edição Extra. Seção 1. P. 1-7.

12. Brasil. Presidência da República. Lei no 10.260 de 12 de julho de 2001 (FIES). Dispõe sobre o Fundo de Financiamento ao Estudante do Ensino Superior e dá outras providências. Brasília: DOU; 13 julho 2001. Seção 1. P. 2.

13. Brasil. Presidência da República. Lei no 11.096 de 13 de janeiro de 2005 (PROUNI). Institui o Programa Universidade para Todos, regulamenta a atuação de entidades beneficentes de assistência social no ensino superior, altera a Lei no 10.891 de 9 de julho de 2004, e dá outras providências. Brasília: DOU; 14 janeiro 2005. Seção 1. P.13.

14. Brasil. Presidência da República. Decreto no 6.096 de 24 de abril de 2007 (REUNI). Institui o Programa de Apoio a Planos de Reestruturação e Expansão das Universidades Federais. Brasília: DOU; 25 abril 2007. Seção 1. P. 7.

15. Pinto VG. A Odontologia Brasileira às Vésperas do Ano 2000: Diagnóstico e Caminhos a Seguir. Brasília: Santos, 1993.

16. IBGE: Instituto Brasileiro de Geografia e Estatística [Internet]. Projeção da população do Brasil e das Unidades da Federação em dezembro de 2016. [acesso em 30 dez 2016] Disponível em: www.ibge.gov.br/apps/população/projeção/

17. Cardoso AL. A odontologia no Brasil e a demanda de políticas regulatórias para o exercício profissional no âmbito do MERCOSUL. [tese]. Rio de Janeiro: Escola Nacional de Saúde Pública/FIOCRUZ, Programa de Pós graduação em Saúde Pública, 2013.

\section{Mini Currículo e Contribuição dos Autores}

Mini Currículo e Contribuição dos Autores

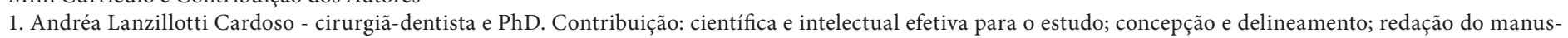
crito; revisão crítica e aprovação final.

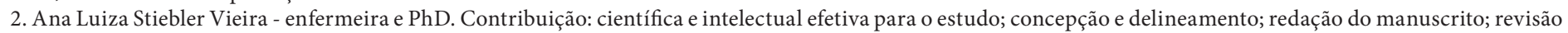
crítica e aprovação final.

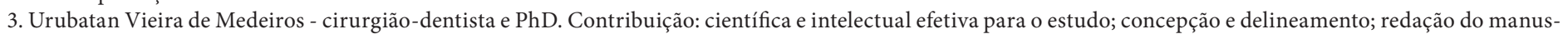
crito; revisão crítica e aprovação final.

Recebido em: 04/04/2017 / Aprovado em: 01/05/2017

Autora Correspondente

Andréa Lanzillotti Cardoso

E-mail: andrealanzi.ppc@gmail.com 